\title{
Evaluation of Prognostic Factors for the Parotid Cancer Treated With Surgery and Postoperative Radiotherapy
}

\author{
Yong-Hyub Kim ${ }^{1}$ (i) $\cdot$ Woong-Ki Chung ${ }^{1}$ (i) $\cdot$ Jae-Uk Jeong ${ }^{1}$ (i) $\cdot$ Ick Joon Cho ${ }^{1}$ (i) $\cdot$ Mee Sun Yoon ${ }^{1}$ (i) $\cdot$ Ju-Young Song ${ }^{1}$ () \\ Taek-Keun Nam ${ }^{1}$ (D) $\cdot$ Sung-Ja Ahn ${ }^{1}$ (D) $\cdot$ Dong Hoon Lee ${ }^{2}$ (D) $\cdot$ Tae Mi Yoon $^{2}$ (D) $\cdot$ Joon Kyoo Lee ${ }^{2}$ (D) $\cdot$ Sang Chul Lim² $^{2}$ \\ Departments of ${ }^{1}$ Radiation Oncology and ${ }^{2}$ Otorhinolaryngology-Head and Neck Surgery, Chonnam National University Hwasun Hospital, \\ Chonnam National University Medical School, Hwasun, Korea
}

Objectives. To investigate the prognostic factors and treatment outcomes of primary parotid carcinoma treated with surgery and postoperative radiotherapy (PORT).

Methods. We reviewed retrospectively 57 patients with primary parotid carcinoma who were treated with surgery and PORT between 2005 and 2014. Superficial parotidectomy was performed in 19 patients, total parotidectomy in 10 patients, and total parotidectomy with lymph node dissection in 28 patients PORT on the tumor bed was performed in 41 patients, while PORT on tumor bed and ipsilateral cervical lymph nodes was performed in 16 patients.

Results. With a median follow-up of 66 months, the 5-year overall survival, disease-free survival, locoregional control, and distant control rates were $77.0 \%, 60.2 \%, 77.6 \%$, and $72.8 \%$, respectively. The 5 -year overall survival by stage was $100 \%, 100 \%, 80.0 \%$, and $46.4 \%$ in stage I, II, III, and IV, respectively. Recurrences at primary lesions were found in seven patients, while at cervical nodes in six patients. Distant recurrences were developed in 12 patients. No patient with the low and intermediate histologic grade developed distant failure. As prognostic factors, the histologic grade for overall survival $(P=0.005)$, pathological T-stage $(P=0.009)$ and differentiation grade $(P=0.009)$ for disease-free survival, pathological T-stage for locoregional control $(P=0.007)$, and lympho-vascular invasion $(P=0.023)$ for distant recurrence were significant on multivariate analysis.

Conclusion. This study revealed that differentiation grade, histologic grade, pathological T-stage, and lympho-vascular invasion were significant independent prognostic factors on clinical outcomes.

Keywords. Parotid Neoplasms; Adjuvant Radiotherapy; Prognosis; Metastases

\section{INTRODUCTION}

Primary parotid carcinoma (PPC) is a rare tumor, representing $1 \%$ to $3 \%$ of all reported head and neck malignancies [1]. The PPC presents heterogeneity regarding malignant potential and

\footnotetext{
- Received March 13, 2019

Revised June 12, 2019

Accepted July 16, 2019

- Corresponding author: Woong-Ki Chung

Department of Radiation Oncology, Chonnam National University Hwasun Hospital, Chonnam National University Medical School, 322 Seoyang-ro, Hwasun-eup, Hwasun 58128, Korea

Tel: +82-61-379-7200, Fax: +82-61-379-7249

E-mail: wkchung@jnu.ac.kr
}

histologic variety [2]. These factors often create difficulties in taking treatment decisions and in predicting prognosis of PPC. Main treatment modality for PPC is surgery. Postoperative radiotherapy (PORT) has been indicated for patients with adverse pathologic features such as positive surgical margin, high histologic grade (H-grade), and advanced stage after surgery [3-6]. Treatment of patients with palpable lymphadenopathy consists of neck dissection followed by neck irradiation [4]. Contrarily, the management of node-negative neck remains controversial. The incidence of occult neck disease is affected by histopathology, T-stage, and grade of differentiation (D-grade) [7-11]. Now, the appropriate treatment of the N0 neck patients with high risk of regional failure seems to be either neck dissection or postop-

Copyright $@ 2020$ by Korean Society of Otorhinolaryngology-Head and Neck Surgery.

This is an open-access article distributed under the terms of the Creative Commons Attribution Non-Commercial License (https://creativecommons.org/licenses/by-nc/4.0)

which permits unrestricted non-commercial use, distribution, and reproduction in any medium, provided the original work is properly cited. 
erative neck irradiation $[9,10,12]$. The current study was undertaken to determine the prognostic factors affecting treatment outcomes in patients with PPC treated with surgery and PORT.

\section{MATERIALS AND METHODS}

\section{Patients}

Eight six patients who received adjuvant PORT under diagnosis of PPC between January 2005 and December 2014 at Chonnam National University Hwasun Hospital were reviewed. Of these, 29 patients with insufficient medical records and/or early follow-up missing were excluded, and finally 57 patients were analyzed. The clinical and pathological data such as age, sex, lymph node status, overall stage, histopathologic findings, surgical procedures, radiation therapy technique, and complications, were evaluated by reviewing the medical records. For the tumor staging, we used the TNM classification of American Joint Committee on Cancer 7th edition. All patients had computed tomography (CT) scanning to evaluate the tumor extent. The D-grade was classified as well (grade 1), moderately (grade 2), and poorly differentiated (grade 3 ). The classification of $\mathrm{H}$-grade was performed by the three-group system proposed by Ettl et al. [13]. This study was approved by the Institutional Review Board of Chonnam National University Hwasun Hospital (IRB No. 2013090).

\section{Surgery}

Out of 57 patients, 19 (33.3\%) with small tumor involving the superficial lobe underwent superficial parotidectomy. Total parotidectomy was performed when the carcinoma was in the deep lobe, or in a tumor diagnosed as malignant tumor by fine needle aspiration cytology (FNAC). Total parotidectomy removing all the parotid tissue while sacrificing the facial nerve was performed when the facial nerve was invaded by carcinoma, or when the facial nerve function was impaired preoperatively. Out of 57 patients, 10 patients $(17.5 \%)$ underwent total parotidectomy without neck dissection. The neck dissection was performed when neck nodes were found by preoperative evaluation such as FNAC or radiologic examination, and in cases suspected with high-grade carcinoma Out of all patients 28 patients

\section{H I GHLI G H T S}

- A retrospective analysis was performed on the 57 patients treated in single institution.

- The 5-year overall survival, locoregional control rates were $77.0 \%$ and $77.6 \%$, respectively.

- Tumor grade, pT-stage (pathological T stage), and lympho-vascular invasion were significant on prognosis.

- Most of treatment failures were distant spread to the lung.
(49.2\%) had total parotidectomy and ipsilateral neck dissection. A total of 17 patients with suspicious radiologic finding of positive neck node had therapeutic neck dissection (TND), and 11 patients had elective neck dissection (END).

\section{Radiation therapy}

In our institute postoperative adjuvant irradiation was recommended when the tumor had pathologically high-risk factors such as positive or close $(<0.5 \mathrm{~cm})$ surgical resection margin, T3-4, high grade, presence of perineural or lymphovascular invasion, and metastatic lymph nodes. PORT was recommended 3-6 weeks after surgery. The median time interval from surgery to PORT was 26 days (range, 14 to 48 days). For radiotherapy dose calculation, all the patients had CT scans of $2.5-\mathrm{mm}$ slice thickness taken at supine position with thermoplastic mask. Irradiation was administered using photons or mixed beams of photons and electrons produced by linear accelerator.The radiation treatment volume was designed to cover the tumor bed with 2-3 cm margins. The median dose was $50.4 \mathrm{~Gy}$ (range, 41.4 to $66.6 \mathrm{~Gy}$ ). Radiation treatment was performed by conventional fractionation using 1.8-2.0 Gy per fraction daily and five times per week. A total of 16 patients $(28.1 \%)$ with high risk factors received neck irradiation including at ipsilateral neck levels I-V. Acute and late complications during or after radiotherapy were recorded by the Radiation Therapy Oncology Group (RTOG) criteria [14].

\section{Follow-up and statistical analysis}

Patients were followed up every $2-3$ months after completion of treatment. Patients had neck and chest CT imaging at 2 month, and 18-Fluoro-deoxyglucose positron emission tomography (FDG-PET) scan at 6 months. Thereafter, neck and chest CT or FDG-PET scan were performed every 6 months. The median follow-up time was 66 months (range, 9 to 124 months). Survival rate was calculated from the date of surgery to death or the last follow-up visit. Survival curves were plotted using the Kaplan-Meier method and compared by the log-rank test. The suggested prognostic factors with $P$-value $<0.1$ from the univariate analysis were included in the multivariate analysis using Cox proportional hazard model. The $P$-value less than 0.05 was considered as statistically significant value. Statistical analysis was performed using IBM SPSS ver. 23.0 (IBM Corp., Armonk, NY).

\section{RESULTS}

\section{Patients}

The median age of patients was 57 years (range, 23 to 82 years). A total of 41 male and 16 female patients were analyzed in this study. The most common pathological type was mucoepidermoid carcinoma $(14,24.5 \%)$, followed by adenocarcinoma, not otherwise specified $(n=8,14.0 \%)$, salivary duct carcinoma $(n=7$, 
Table 1. Patient and treatment characteristics

\begin{tabular}{|c|c|}
\hline Variable & Value \\
\hline Age (yr) & $57(23-82)$ \\
\hline Sex (male:female) & 41 (71.9):16 (27.6) \\
\hline \multicolumn{2}{|l|}{ Histological type } \\
\hline Low grade (MEC:AdCC:CXPA:ACC:EMC) & $\begin{array}{c}7(12.3): 6(10.5): \\
5(8.8): 4(7.0): 3(5.3)\end{array}$ \\
\hline Intermediate grade (MEC) & $2(3.5)$ \\
\hline $\begin{array}{l}\text { High grade } \\
\text { (ADC:SDC:SCC:MEC:LEC:OCC:LCC) }\end{array}$ & $\begin{array}{c}8(14.0): 7(12.3): 6(10.5): \\
5(8.8): 2(3.5): 1(1.8): 1(1.8)\end{array}$ \\
\hline pT-stage (T1:T2:T3:T4) & $\begin{array}{l}12(21.1): 21(36.8): \\
11(19.3): 13(22.8)\end{array}$ \\
\hline pN-stage (N0:N1:N2b) & $39(68.4): 6(10.5): 12(21.1)$ \\
\hline pStage (I:II:III:IVA) & $\begin{array}{l}10(17.5): 16(28.1): \\
11(19.3): 20(35.1)\end{array}$ \\
\hline Tumor size $(\mathrm{cm})$ & $3(1-6.3)$ \\
\hline Tumor grade (well:moderately:poorly) & $30(52.6): 9(15.8): 18(31.6)$ \\
\hline \multicolumn{2}{|l|}{ Surgical margin } \\
\hline Negative & $45(78.9)$ \\
\hline Positive+close (<5 mm) & $12(21.1)$ \\
\hline Perineural invasion (no:yes) & $47(82.5): 10(17.5)$ \\
\hline Lymphovascular invasion (no:yes) & $48(84.2): 9(15.8)$ \\
\hline \multicolumn{2}{|l|}{ Surgery type } \\
\hline Superficial parotidectomy & $19(33.3)$ \\
\hline Total parotidectomy & $10(17.5)$ \\
\hline Total parotidectomy and neck dissection & $28(49.2)$ \\
\hline Therapeutic neck dissection & 17 \\
\hline Elective neck dissection & 11 \\
\hline \multicolumn{2}{|l|}{ Radiation field } \\
\hline Parotid bed & $41(71.9)$ \\
\hline Parotid bed+ipsilateral cervical neck node & $16(28.1)$ \\
\hline Radiation dose (Gy) & $50.4(41.4-66.6)$ \\
\hline Follow-up period (mon) & $66(9-124)$ \\
\hline
\end{tabular}

Values are presented as median (range) or number (\%).

MEC, mucoepidermoid carcinoma; AdCC, adenoid cystic carcinoma; CXPA, carcinoma ex pleomorphic adenoma; ACC, acinic cell carcinoma; EMC, epithelial-myoepithelial carcinoma; ADC, adenocarcinoma, not otherwise specified; SDC, salivary duct carcinoma; SCC, squamous cell carcinoma; LEC, lymphoepithelial carcinoma; OCC, oncocytic carcinoma; LCC, large cell undifferentiated carcinoma; $p$, pathologic.

$12.3 \%$ ), squamous cell carcinoma ( $n=6,10.5 \%)$, adenoid cystic carcinoma $(n=6,10.5 \%)$, carcinoma ex pleomorphic adenoma ( $n=5,8.8 \%)$, acinic cell carcinoma $(n=4,7.0 \%)$, epithelial-myoepithelial carcinoma $(n=3,5.3 \%)$, lymphoepithelial carcinoma $(\mathrm{n}=2,3.5 \%)$, oncocytic carcinoma $(\mathrm{n}=1,1.8 \%)$, and large cell undifferentiated $(\mathrm{n}=1,1.8 \%)$. The TNM classification was as follows: T1, 12 patients (21.1\%); T2, 21 (36.8\%); T3, 11 (19.3\%); T4, 13 (22.8\%); N0, 39 (68.4\%); N1, 6 (10.5\%); N2b, 12 $(21.1 \%)$, respectively (Table 1$)$. There was no acute grade 3 or higher toxicity during PORT. Acute grade 1-2 buccal mucositis occurred in seven patients. After completion of radiotherapy, two patients having grade 3 hearing impairment were treated by hearing aid. There was no treatment-related death or late toxicity of more than grade 4 .

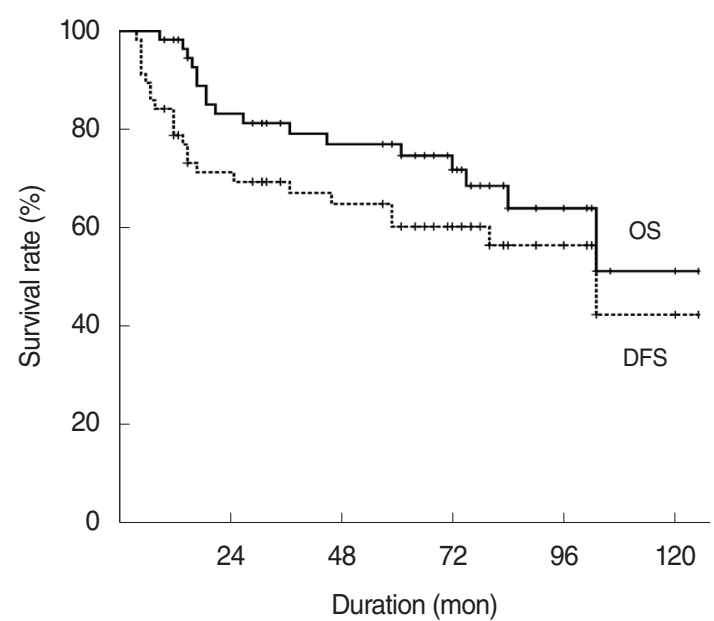

Fig. 1. Overall survival (OS) and disease-free survival (DFS) rates for 57 patients with parotid gland carcinoma.

\section{Overall survival and disease-free survival}

The overall survival rate at 5 and 10 years was $77.0 \%$ and $51.2 \%$, respectively (Fig. 1). The overall survival by stage were $100 \%$, $100 \%, 80.0 \%$, and $46.4 \%$ in stage I, II, III, and IV, respectively. Univariate analysis revealed that female, lower T stage, pathologically node negative, lower D-grade, lower histologic tumor grade (H-grade) and no lympho-vascular invasion (LVI) were significantly associated with better survival (Table 2). Multivariate analysis revealed higher $\mathrm{H}$-grade were associated with worse OS (Table 3).

The 5- and 10-year disease-free survival (DFS) rates were 60.2\% and $42.4 \%$, respectively (Fig. 1). In the univariate analysis, age at diagnosis, sex, pT-stage (pathological T stage), pN-stage, D-grade, $\mathrm{H}$-grade, perineural invasion (PNI), and LVI were significantly associated with DFS. In multivariate analysis, T-stage $(P=0.009$; hazard ratio $[\mathrm{HR}], 3.628)$ and D-grade $(P=0.009, \mathrm{HR}, 3.460)$ were independent prognostic factors for DFS (Table 3 ).

\section{Locoregional recurrence and distant metastasis}

The locoregional control rate at 5 years was $77.6 \%$ in all patients (Fig. 2). Out of 13 patients who had locoregional recurrences (LRR), seven patients had local failures and six had regional nodal recurrences (Fig. 3, Supplementary Table 1). Out of six patients with nodal recurrences, four $(66.7 \%)$ were in pT4a stage and six in high H-grade (Table 4). One of six patients with regional nodal recurrences had a simultaneous distant metastasis to the lung. There was no significant difference in locoregional failure rates by radiation dose between two groups ( $<55 \mathrm{~Gy}$; $17.8 \%, \geq 55 \mathrm{~Gy} ; 33.9 \%, P=0.353$ ). Univariate analysis revealed that gender, pT-stage, and pN-stage were associated with locoregional control. But, marginal status, PNI, and LVI were not associated with LRR (Table 2). On multivariate analysis, T-stage was significant ( $P=0.007$; HR, 8.189) as a predictor of LRR (Table 3).

The distant control rate at 5 years was $72.8 \%$ (Fig. 2). Distant 
Table 2. Univariate analysis for factors associated with treatment outcome

\begin{tabular}{|c|c|c|c|c|c|c|c|c|c|}
\hline \multirow{2}{*}{ Characteristics } & \multirow{2}{*}{ No. (\%) } & \multicolumn{2}{|c|}{ 5-Year OS } & \multicolumn{2}{|c|}{ 5-Year DFS } & \multicolumn{2}{|c|}{ 5-Year LRC } & \multicolumn{2}{|c|}{ 5-Year DC } \\
\hline & & Rate (\%) & $P$-value & Rate (\%) & $P$-value & Rate (\%) & $P$-value & Rate (\%) & $P$-value \\
\hline Age (yr) & & & 0.056 & & 0.029 & & 0.051 & & 0.543 \\
\hline$\leq 60$ & $35(61.4)$ & 87.6 & & 68.8 & & 85.4 & & 74.9 & \\
\hline$>60$ & $22(38.6)$ & 59.6 & & 45.4 & & 63.5 & & 69.3 & \\
\hline Sex & & & 0.009 & & 0.004 & & 0.046 & & 0.029 \\
\hline Male & $41(71.9)$ & 69.4 & & 47.4 & & 70.5 & & 62.5 & \\
\hline Female & $16(28.1)$ & 93.8 & & 87.5 & & 93.8 & & 93.8 & \\
\hline pT-stage & & & 0.001 & & $<0.001$ & & $<0.001$ & & 0.033 \\
\hline T1-2 & $33(57.9)$ & 92.9 & & 79.8 & & 93.8 & & 82.7 & \\
\hline T3-4 & $24(42.1)$ & 56.3 & & 33.9 & & 54.3 & & 59.5 & \\
\hline pN-stage & & & 0.014 & & 0.001 & & 0.006 & & 0.022 \\
\hline NO & $39(68.4)$ & 88.6 & & 68.6 & & 85.8 & & 80.0 & \\
\hline $\mathrm{N}+$ & $18(31.6)$ & 51.6 & & 42.4 & & 59.5 & & 57.9 & \\
\hline D-grade & & & 0.002 & & $<0.001$ & & 0.514 & & $<0.001$ \\
\hline G1-2 & $39(68.4)$ & 86.1 & & 78.8 & & 78.8 & & 89.1 & \\
\hline G3 & $18(31.6)$ & 57.5 & & 16.9 & & 75.1 & & 35.4 & \\
\hline H-grade & & & $<0.001$ & & $<0.001$ & & 0.036 & & $<0.001$ \\
\hline Low\& intermediate & $27(47.4)$ & 96.0 & & 88.9 & & 88.9 & & 100 & \\
\hline high & $30(52.6)$ & 60.9 & & 34.0 & & 66.7 & & 49.5 & \\
\hline SM & & & 0.674 & & 0.268 & & 0.714 & & 0.440 \\
\hline Negative & 45 (78.9) & 81.2 & & 64.1 & & 78.6 & & 75.9 & \\
\hline Positive & $12(21.1)$ & 61.4 & & 45.0 & & 74.1 & & 60.2 & \\
\hline PNI & & & 0.144 & & 0.023 & & 0.603 & & 0.038 \\
\hline Negative & 47 (82.5) & 81.3 & & 67.6 & & 79.7 & & 78.7 & \\
\hline Positive & $10(17.5)$ & 60.0 & & 30.0 & & 68.6 & & 48.0 & \\
\hline LVI & & & 0.017 & & $<0.001$ & & 0.323 & & $<0.001$ \\
\hline Negative & 48 (84.2) & 84.6 & & 68.4 & & 80.1 & & 81.6 & \\
\hline Positive & $9(15.7)$ & 37.5 & & 13.9 & & 63.5 & & 17.8 & \\
\hline CN7 invasion & & & 0.269 & & 0.065 & & 0.364 & & 0.153 \\
\hline Negative & $33(57.9)$ & 82.9 & & 70.4 & & 81.3 & & 79.4 & \\
\hline Positive & $24(42.1)$ & 69.3 & & 46.7 & & 71.9 & & 64.3 & \\
\hline
\end{tabular}

OS, overall survival; DFS, disease-free survival; LRC, locoregional control; DC, distant control; p, pathologic; D, differentiation; $H$, histologic; SM, surgical margin; PNI, perineural invasion; LVI, lymphovascular invasion; CN, cranial nerve.

Table 3. Multivariate analysis by prognostic factors

\begin{tabular}{lccc}
\hline Variable & \multicolumn{1}{c}{ Factor } & $\mathrm{HR}(95 \% \mathrm{Cl})$ & P-value \\
\hline $\begin{array}{l}\text { Overall survival } \\
\text { H-grade }\end{array}$ & $\begin{array}{c}\text { Low \& intermediate } \\
\text { vs. high }\end{array}$ & $\begin{array}{c}18.148 \\
(2.397-137.279)\end{array}$ & 0.005 \\
$\begin{array}{l}\text { Disease-free survival } \\
\text { T-stage }\end{array}$ & T1-2 vs. T3-4 & $\begin{array}{c}3.628 \\
(1.383-9.514)\end{array}$ & 0.009 \\
D-grade & G1-2 vs. G3 & $\begin{array}{c}3.460 \\
(1.373-8.722)\end{array}$ & 0.009 \\
Locoregional control & T1-2 vs. T3-4 & 8.189 & 0.007 \\
T-stage & & $(1.798-37.302)$ & \\
Distant control & No vs. yes & 19.179 & 0.023 \\
LVI & & $(1.513-243.153)$ & \\
\hline
\end{tabular}

$\mathrm{HR}$, hazard ratio; $\mathrm{Cl}$, confidential interval; $\mathrm{H}$, histologic; $\mathrm{D}$, differentiation; $\mathrm{LVI}$, lymphovascular invasion. metastasis developed in 14 patients after a median of 13 months (range, 4 to 59 months) after treatment completion. The most common site was the lung (11 patients) (Supplementary Table 2). Sex, pT-stage, pN-stage, D-grade, H-grade, PNI and LVI were associated with increased risk of distant metastasis in univariate analysis (Table 2). There was no distant recurrence in the lower histologic tumor grade. On multivariate analysis LVI as a continuous variable remained associated with risk of distant metastasis (Table 3).

\section{Analysis of patients with recurrence of neck disease}

The sites of nodal recurrence were the ipsilateral level Ib, IIa, $\mathrm{Vb}$, retropharyngeal lymph node, and supraclavicular lymph nodes. There was no contralateral neck recurrence. Regional recurrence was appeared in six patients who had neck dissection (END, two patients; TND, four patients). Out of six patients, four had neck node irradiation (Table 4). Patients irradiated in tumor bed and neck node bearing area had worse prognostic factors and more 


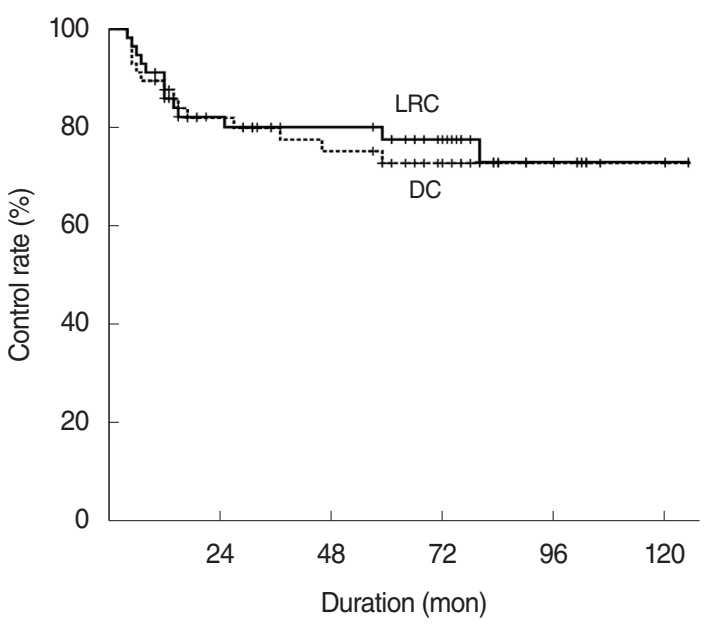

Fig. 2. Locoregional control (LRC) and distant control (DC) rates for 57 patients with parotid gland carcinoma.

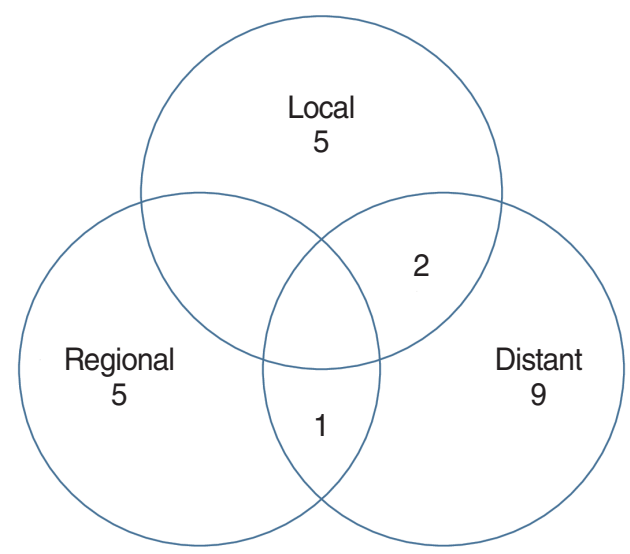

Fig. 3. Treatment failure patterns after postoperative radiotherapy with parotid gland carcinoma. Of 22 patients of failures, seven (12.3\%) of local, six (10.5\%) of regional, and $12(21.1 \%)$ of distant failure were observed, respectively.

Table 4. Clinicopathological details of patients with recurrent neck disease

\begin{tabular}{|c|c|c|c|c|c|c|c|c|c|c|c|}
\hline No. & Age (yr) & Sex & $\mathrm{cN}$ & ND & Histology & D-grade & H-grade & Neck irradiation & pT & $\mathrm{pN}$ & Recurrence of neck \\
\hline 1 & 62 & Male & N1 & Yes & OCC & Poorly & High & No & $4 a$ & $2 b$ & $\mathrm{Vb}$ \\
\hline 2 & 49 & Male & NO & Yes & MEC & Poorly & High & No & $4 a$ & 0 & $\mathrm{lb}$ \\
\hline 3 & 69 & Male & NO & Yes & SCC & Moderately & High & Yes & 3 & 0 & Retropharyngeal \\
\hline 4 & 69 & Male & NO & Yes & $A D C$ & Moderately & High & Yes & 1 & $2 b$ & I-V \\
\hline 5 & 59 & Male & NO & Yes & SCC & Well & High & Yes & $4 a$ & 0 & SCL \\
\hline 6 & 54 & Male & N2 & Yes & SCC & Moderately & High & Yes & $4 a$ & $2 b$ & Ila \\
\hline
\end{tabular}

cN, clinical N stage; ND, neck dissection; D, differentiation; $\mathrm{H}$, histologic; $\mathrm{pT}$, pathological T stage; pN, pathological N stage; OCC, oncocytic carcinoma; MEC, mucoepidermoid carcinoma; SCC, squamous cell carcinoma; ADC, adenocarcinoma, not otherwise specified; SCL, supraclavicular lymph node.

regional recurrence than tumor bed only $(4 / 16,25.0 \%$ vs. $2 / 41$, $4.8 \%$ ). The 16 patients given irradiation in tumor bed and neck node bearing area were all men and had significantly older age $(P=0.033)$, more pathological node positivity $(P<0.001)$, higher histological tumor grade $(P=0.001)$, and more LVI $(P=0.001)$ than patients without neck irradiation. The neck recurrence rate of T3-4 patients $(5 / 24,20.8 \%)$ was higher than T1-2 group $(1 / 33,3.0 \%)$, but statistically not significant $(P=0.073)$.

Among patients with pathological node negative, three patients $(3 / 39,7.7 \%)$ had regional nodal failure. In the subgroup analysis of pathological node negative, T3-4 stage $(P=0.031)$ and histologic tumor grade $(P=0.050)$ were associated with regional nodal recurrence.

\section{DISCUSSION}

It is generally agreed that combination therapy with a complete surgical resection followed by radiation therapy in high risk parotid carcinoma is the rational approach to improve treatment outcome [3-6]. Parotid carcinoma is a rare disease and showed heterogenous nature, hence treatment outcomes vary widely among patients. It is important to identify prognostic factors to improve treatment outcomes. Chen et al. [15] reported a 10year local-regional recurrence rate ranging from $37 \%$ to $63 \%$ after surgery alone for parotid carcinoma with high risk factors, and suggested that adjuvant postoperative radiation should routinely be offered. Garden et al. [16] reported 5- and 10-year local control rates of $92 \%$ and $90 \%$ by surgery and postoperative adjuvant radiation therapy, respectively, in patients with parotid carcinoma with inadequate margins, extraglandular disease extension, PNI, and nodal disease. Mendenhall et al. [17] reported improved local control rate in patients with close or positive resection margin, high-grade histology, involved lymph node, PNI and or endothelial-lined space invasion by postoperative adjuvant radiation therapy.

TNM staging is a good prognostic factor for treatment decision. T stage had a significant influence on survival $[3,5]$. High T stages (T3-4) were also independent prognostic factors for the presence of positive nodes [11]. Al-Mamgani et al. [18] reported that the $\mathrm{T}$ stage was an important independent factor for DFS. Also, Chen et al. [15] showed that stage T3-4 disease that was treated with gross total tumor resection without adjuvant PORT was a parameter predictive of LRR. T3-4 tumors have a significant risk of local relapse following surgical excision and could be reduced by adjuvant radiotherapy. According to Terhaard et 
al. [4], combined treatment for T3-4 tumors revealed significantly better local control than surgery alone $(84 \%$ vs. $18 \%, P<0.001)$. In our study also, $\mathrm{T}$ stage was a significant factor for locoregional control on multivariate analysis.

Treatment of parotid carcinoma with clinically lymph node metastases consists of neck dissection and postoperative radiation. Postoperative locoregional radiotherapy for the pathological positive neck node significantly improved regional control (PORT, $86 \%$ vs. surgery alone, 62\%) [4]. In the study by Chen et al. [8], postoperative elective neck irradiation to patients with clinically N0 carcinomas of the salivary glands reduced the 10year nodal relapse rate from $26 \%$ to $0 \%(P<0.001)$. They proposed that elective neck irradiation effectively prevents nodal failure and should be used for selected patients at high risk for regional failure. Al-Mamgani et al. [18] reported that none of the high-risk node-negative patients who received elective nodal irradiation developed regional failure.

According to the National Cancer Data Base study of 22,653 patients with parotid cancer, high $\mathrm{T}$ stage and grade are significant independent predictive factors of nodal metastasis for most histopathologies [11]. In our study, on the multivariate analysis T3-4 stage was significant factor for LRR in comparison with T1-2 after treatment. T3-4 stage and histologic tumor grade were associated with regional nodal recurrence in patients with pathologically negative neck node. Such patients with at high risk for regional failure need comprehensive treatment. Adjuvant chemoradiotherapy (CRT) using intensity modulated radiotherapy is well tolerated and could provide excellent local control in a properly selected, high-risk patient with salivary gland cancer [19]. However, benefit of a postoperative CRT for highrisk major salivary gland carcinomas is still a subject of debate $[20,21]$. The RTOG 1008 randomized trial for adjuvant concurrent radiation and weekly cisplatin versus radiation alone in resected high-risk malignant salivary gland tumors is currently ongoing. Postoperative CRT should be considered based on specific considerations in selected patient.

Grading of parotid carcinoma is an important predictor of survival $[5,18]$. It may predict the risk of disease recurrence and provide a strategy for the extent of surgery and the requirement for adjuvant therapy. In a systematic review, high-grade tumor has been implicated with adverse survival compared with low grade tumors [5]. Also, retrospective review of the National Cancer Data Base in the U. S. records has identified that high grade tumor is associated with increased rates of recurrence [11]. Highgrade cancers are more likely to develop metastasis locally and distantly as compared to low-grade tumors. In our study, grade was significant risk factor in DFS rate, $78.8 \%$ in grade 1 to 2 tumors and $16.9 \%$ in grade 3 tumors.

Histopathological type is one of the important prognostic factors which are associated with various clinical course and treatment outcome [2]. Some studies reported group stratification by histology and grade, which are considered to be important fac- tors affecting local control or distant metastasis $[13,22,23]$. In our study, three histological subgroups were classified by grade and histology based established criteria [13]. In our study, overall survival rate of low and intermediate histological subgroup at 5 year was $96.0 \%$. Distant recurrence was not developed in the low to intermediate group. In this study, six patients with nodal failures were all in the high-risk group.

According to the National Comprehensive Cancer Network guidelines, PORT is recommended for patients with perineural, vascular, and lymphatic invasion [24]. Ali et al. [25] reported that vascular and PNI were predictive factors for recurrence of carcinoma of the major salivary glands. Kim et al. [26] reported that lymphovascular invasion was a significant independent prognostic factor in patients with salivary duct carcinoma of the major salivary glands. In the case of PNI of a major nerve, the cranial nerve pathways up to the base of the skull must be included in the target volume of radiotherapy. Therefore, the PNI is important in the planning of radiotherapy. However, in this study the PNI did not reveal prognostic significance for OS, DFS, local control, and distant metastasis. LVI was significant for distant metastasis in our study. Out of nine patients, six patients with LVI had distant metastasis after treatment.

In salivary gland malignancies, the incidence of distant metastasis varied from $20 \%$ to $50 \%$ and was affected by histological types and tumor site [27]. In this study, 12 patients $(20.7 \%)$ developed distant metastasis as the first site of failure, and major cause for treatment failure was distant metastases. Development of appropriate systemic therapy at high risk of DM is mandatory to improve clinical outcome [28]. Cytotoxic chemotherapy is generally employed for palliative purposes in patients with metastatic and/or recurrent disease. Numerous studies of molecular targeted therapies are in progress today [29]. Recently, a study showed that programmed death ligand-1 (PD-L1) expression in salivary gland cancer was significantly associated with poor DFS on multivariate analysis [30]. They also reported that PD-L1 expression was significantly associated with human epidermal growth factor receptor 2 (HER2) overexpression and suggested that the combination therapy of trastuzumab and anti-PD-1/ PD-L1 antibody might provide a more effective treatment outcome.

In our institute, the PORT has been recommended in parotid carcinoma with high risk factors such as high-grade histology, high T-stage, perineural/vascular/lymphatic invasion, a deep lobe location, positive or close surgical margin, and lymph node metastases. This retrospective analysis has several limitations such as small sample size, various rare histological subtypes, insufficient medical records, and early follow-up missing. However, the histologic tumor grade, advanced T3-4 stage, high grade of tumor differentiation and lympho-vascular invasion were revealed as significant prognostic factors for treatment outcome. Especially, advanced T-stage was found to be a significant prognostic factor for locoregional recurrence. Most of treatment failures 
were distant spread to the lung. Further studies are required to reduce the risk of distant metastasis.

\section{CONFLICT OF INTEREST}

No potential conflict of interest relevant to this article was reported.

\section{ORCID}

$\begin{array}{ll}\text { Yong-Hyub Kim } & \text { https://orcid.org/0000-0001-5447-2538 } \\ \text { Woong-Ki Chung } & \text { https://orcid.org/0000-0001-6049-3263 } \\ \text { Jae-Uk Jeong } & \text { https://orcid.org/0000-0002-4580-2854 } \\ \text { Ick Joon Cho } & \text { https://orcid.org/0000-0002-4187-1043 } \\ \text { Mee Sun Yoon } & \text { https://orcid.org/0000-0002-0996-926X } \\ \text { Ju-Young Song } & \text { https://orcid.org/0000-0002-6882-8555 } \\ \text { Taek-Keun Nam } & \text { https://orcid.org/0000-0003-1229-8468 } \\ \text { Sung-JaAhn } & \text { https://orcid.org/0000-0002-3066-2617 } \\ \text { Dong Hoon Lee } & \text { https://orcid.org/0000-0001-9288-5368 } \\ \text { Tae MiYoon } & \text { https://orcid.org/0000-0002-6070-9113 } \\ \text { Joon Kyoo Lee } & \text { https://orcid.org/0000-0002-7542-9616 } \\ \text { Sang Chul Lim } & \text { https://orcid.org/0000-0001-5610-1554 }\end{array}$

\section{AUTHOR CONTRIBUTIONS}

Conceptualization:WKC. Data curation: IJC, JUJ. Formal analysis \& Methodology: WKC. Project administration: WKC, YHK. Visualization: YHK. Writing - original draft: YHK. Writing - review \& editing: all authors.

\section{SUPPLEMENTARY MATERIALS}

Supplementary materials can be found via https://doi.org/10. 21053/ceo.2019.00388.

\section{REFERENCES}

1. Calearo C, Pastore A, Storchi OF, Polli G. Parotid gland carcinoma: analysis of prognostic factors. Ann Otol Rhinol Laryngol. 1998 Nov; 107(11 Pt 1):969-73.

2. Lewis AG, Tong T, Maghami E. Diagnosis and management of malignant salivary gland tumors of the parotid gland. Otolaryngol Clin North Am. 2016 Apr;49(2):343-80.

3. Terhaard CH, Lubsen H,Van derTweel I, Hilgers FJ, EijkenboomWM, Marres HA, et al. Salivary gland carcinoma: independent prognostic factors for locoregional control, distant metastases, and overall survival: results of the Dutch head and neck oncology cooperative group. Head Neck. 2004 Aug;26(8):681-92.

4. Terhaard CH, Lubsen H, Rasch CR, Levendag PC, Kaanders HH,
Tjho-Heslinga RE, et al.The role of radiotherapy in the treatment of malignant salivary gland tumors. Int J Radiat Oncol Biol Phys. 2005 Jan;61(1):103-11.

5. Jeannon JP, Calman F, Gleeson M, McGurk M, Morgan P, O'Connell $\mathrm{M}$, et al. Management of advanced parotid cancer: a systematic review. Eur J Surg Oncol. 2009 Sep;35(9):908-15.

6. Noh JM, Ahn YC, Nam H, ParkW, Baek CH, Son YI, et al. Treatment results of major salivary gland cancer by surgery with or without postoperative radiation therapy. Clin Exp Otorhinolaryngol. 2010 Jun;3(2):96-101.

7. Stennert E, Kisner D, Jungehuelsing M, Guntinas-Lichius O, Schroder $\mathrm{U}$, Eckel HE, et al. High incidence of lymph node metastasis in major salivary gland cancer. Arch Otolaryngol Head Neck Surg. 2003 Jul; 129(7):720-3.

8. Chen AM, Garcia J, Lee NY, Bucci MK, Eisele DW. Patterns of nodal relapse after surgery and postoperative radiation therapy for carcinomas of the major and minor salivary glands: what is the role of elective neck irradiation? Int J Radiat Oncol Biol Phys. 2007 Mar; 67(4):988-94.

9. Ali S, Palmer FL, DiLorenzo M, Shah JP, Patel SG, Ganly I.Treatment of the neck in carcinoma of the parotid gland.Ann Surg Oncol. 2014 Sep;21(9):3042-8.

10. Lau VH, Aouad R, Farwell DG, Donald PJ, Chen AM. Patterns of nodal involvement for clinically N0 salivary gland carcinoma: refining the role of elective neck irradiation. Head Neck. 2014 Oct;36(10): 1435-9.

11. Shinomiya H, Otsuki N, Yamashita D, Nibu K. Patterns of lymph node metastasis of parotid cancer. Auris Nasus Larynx. 2016 Aug;43(4): 446-50.

12. Terhaard $\mathrm{CH}$. Postoperative and primary radiotherapy for salivary gland carcinomas: indications, techniques, and results. Int J Radiat Oncol Biol Phys. 2007;69(2 Suppl):S52-5.

13. EttlT, Schwarz-Furlan S, Gosau M, ReichertTE. Salivary gland carcinomas. Oral Maxillofac Surg. 2012 Sep;16(3):267-83.

14. Cox JD, Stetz J, Pajak TF. Toxicity criteria of the Radiation Therapy Oncology Group (RTOG) and the European Organization for Research and Treatment of Cancer (EORTC). Int J Radiat Oncol Biol Phys. 1995 Mar;31(5):1341-6.

15. Chen AM, Granchi PJ, Garcia J, Bucci MK, Fu KK, Eisele DW. Localregional recurrence after surgery without postoperative irradiation for carcinomas of the major salivary glands: implications for adjuvant therapy. Int J Radiat Oncol Biol Phys. 2007 Mar;67(4):982-7.

16. Garden AS, el-Naggar AK, Morrison WH, Callender DL, Ang KK, Peters LJ. Postoperative radiotherapy for malignant tumors of the parotid gland. Int J Radiat Oncol Biol Phys. 1997 Jan;37(1):79-85.

17. Mendenhall WM, Morris CG, Amdur RJ, Werning JW, Villaret DB. Radiotherapy alone or combined with surgery for salivary gland carcinoma. Cancer. 2005 Jun;103(12):2544-50.

18. Al-Mamgani A, van Rooij P, Verduijn GM, Meeuwis CA, Levendag PC. Long-term outcomes and quality of life of 186 patients with primary parotid carcinoma treated with surgery and radiotherapy at the Daniel den Hoed Cancer Center. Int J Radiat Oncol Biol Phys. 2012 Sep;84(1):189-95.

19. Schoenfeld JD, Sher DJ, Norris CM Jr, Haddad RI, Posner MR, BalboniTA, et al. Salivary gland tumors treated with adjuvant intensitymodulated radiotherapy with or without concurrent chemotherapy. Int J Radiat Oncol Biol Phys. 2012 Jan;82(1):308-14.

20. Amini A, WaxweilerTV, Brower JV, Jones BL, McDermott JD, Raben $\mathrm{D}$, et al.Association of adjuvant chemoradiotherapy vs radiotherapy alone with survival in patients with resected major salivary gland carcinoma: data from the national cancer data base. JAMA Otolaryngol Head Neck Surg. 2016 Nov;142(11):1100-10.

21. Hsieh CE, Lin CY, Lee LY, Yang LY, Wang CC, Wang HM, et al. Adding concurrent chemotherapy to postoperative radiotherapy improves 
locoregional control but not overall survival in patients with salivary gland adenoid cystic carcinoma: a propensity score matched study. Radiat Oncol. 2016 Mar;11:47.

22. Mifsud MJ,Tanvetyanon T, Mccaffrey JC, Otto KJ, Padhya TA, Kish J, et al. Adjuvant radiotherapy versus concurrent chemoradiotherapy for the management of high-risk salivary gland carcinomas. Head Neck. 2016 Nov;38(11):1628-33.

23. Therkildsen MH, Christensen M,Andersen LJ, SchiodtT, Hansen HS. Salivary gland arcinomas: prognostic factors. Acta Oncol. 1998;37 (7-8):701-13.

24. National Comprehensive Cancer Network. Head and Neck Cancer Cancers: v1.2018 [Internet]. Plymouth Meeting, PA: National Comprehensive Cancer Network; 2018 [cited 2019 Aug 1]. Available from: https://www.nccn.org/professionals/physician_gls/pdf/headand-neck.pdf.

25. Ali S, Palmer FL, Yu C, DiLorenzo M, Shah JP, Kattan MW, et al. A predictive nomogram for recurrence of carcinoma of the major salivary glands. JAMA Otolaryngol Head Neck Surg. 2013 Jul;139(7): 698-705.
26. Kim JY, Lee S, Cho KJ, Kim SY, Nam SY, Choi SH, et al. Treatment results of post-operative radiotherapy in patients with salivary duct carcinoma of the major salivary glands. Br J Radiol. 2012 Oct;85 (1018):e947-52.

27. Mariano FV, da Silva SD, Chulan TC, de Almeida OP, Kowalski LP. Clinicopathological factors are predictors of distant metastasis from major salivary gland carcinomas. Int J Oral Maxillofac Surg. 2011 May;40(5):504-9.

28. Poorten VV, Meulemans J, Delaere P, Nuyts S, Clement P. Molecular markers and chemotherapy for advanced salivary cancer. Curr Otorhinolaryngol Rep. 2014 Jun;2(2):85-96.

29. Schmitt NC, Kang H, Sharma A. Salivary duct carcinoma: an aggressive salivary gland malignancy with opportunities for targeted therapy. Oral Oncol. 2017 Nov;74:40-8.

30. Mukaigawa T, Hayashi R, Hashimoto K, Ugumori T, Hato N, Fujii S. Programmed death ligand-1 expression is associated with poor disease free survival in salivary gland carcinomas. J Surg Oncol. 2016 Jul;114(1):36-43. 